\title{
Análise da sustentabilidade de produtos através do uso de modelagem
}

\section{Sustainability assessment of product design using models}

Paulo Cesar Machado Ferroli ${ }^{1}$

Lisiane Ilha Librelotto ${ }^{2}$ 


\section{Resumo}

O conceito moderno de sustentabilidade reescreve de modo geral o conceito de design. A evolução nas abordagens dos programas de qualidade $e$ produtividade fez com que o conceito de melhoria contínua tomasse um novo aspecto. $O$ respeito à natureza, considerado como diferencial no final do século passado, adquire um caráter distinto: agora é obrigatório. Contudo, no cerne da atividade de design, está a constante inovação, a satisfação dos desejos dos clientes e a oferta contínua de novos produtos, objetivando a conquista do público-alvo. Aliar essa necessidade com a questão ambiental é muito complexo, pois em primeiro momento o eco-design prioriza a redução, o aumento do ciclo de vida dos produtos, o reaproveitamento e a reciclagem, por exemplo. Ou seja, parecem conceitos opostos. Na busca por tentar conseguir um equilíbrio entre os conceitos, surge a sustentabilidade, mais ampla do que somente o eco-design, pois engloba as questões econômicas, sociais e ambientais em um mesmo patamar de importância. $O$ trabalho atual pretende contribuir nessa discussão mostrando a aplicação dos conceitos da sustentabilidade aplicados em projeto, mediante a experimentação em modelos e protótipos.

\section{Abstract}

The modern concept of sustainability is rewriting the concept of design. The evolution of the approach to quality and productivity programs has given a new dimension to the concept of continuous development. Until the end of last century, taking the environmental sustainability in a project into consideration was considered a positive additon, but now it has acquired a different aspect: it is mandatory. Nonetheless, the core of design activity aims at meeting certain needs: the need of constant innovation, the need of satisfying the customers and the need to continuously offer new products to those target customers. Allying those needs to the environmental issue in order to achieve an ecodesign is highly complex, as it involves reducing the use of raw materials, extendind the products' lifecycle; reusing and recycling some materials; just to mention some practical examples. Taking this into consideration, the terms design and eco-design seem like opposing concepts. Seeking for a balance between such concepts, the term sustainability arises, for as it carries a wider meaning than both either of the previous terms. Sustainability implies that three aspects of an this issue are approached with equal importance: the envi-

Palavras-Chave: Modelos; Protótipos; Sustentabilidade, Design.

ISSN: 1808-3129

\footnotetext{
${ }^{1}$ Engenheiro Mecânico, Doutor em Engenharia de Produção, professor do design, adj. 3, CCE -UFSC Brasil ferroli@cce.ufsc.br

${ }^{2}$ Eng. Civil, Doutora em Engenharia de Produção, professor pós-arq UFSC - Brasil liane.librelotto@arq.ufsc.br
} 
ronmental aspect, the social aspect and the economic aspect. This present work intends to contribute to this debate by demonstrating the concepts of sustainability applied to a project, through model and prototype experiments.

Keywords: prototypes; models; sustainability; design. 


\section{Introdução}

De acordo com Penna (2002), modelos e protótipos são usados para reduzir incertezas, que podem ser provenientes de: viabilidade de negócio de um produto que está sendo desenvolvido, desempenho tecnológico, teste de conceitos, melhor compreensão de requisitos técnicos e formais, aparência do produto e sua usabilidade.

Neste artigo, será utilizado o conceito de Manzini e Vezzoli (2008), onde design de produtos é entendido de acordo com seu significado amplo e atual, não se aplicando apenas ao produto físico (definido por material, forma e função), mas estendendo-se ao sistema - produto, ou seja, ao conjunto integrado de produto, serviço e comunicação. Dentro dessa linha de pensamento os autores destacam que o design é a atividade que deve "ligar" o tecnicamente possível com o ecologicamente necessário atuando dentro de quatro níveis de interferência: redesign ambiental de produtos já existentes; projeto de novos produtos para substituição dos atuais; projeto de novos produtos - serviços intrinsecamente sustentáveis; e proposta de novos cenários para um novo estilo de vida sustentável (figura 1 - adaptada de Manzini e Vezzoli, 2008).

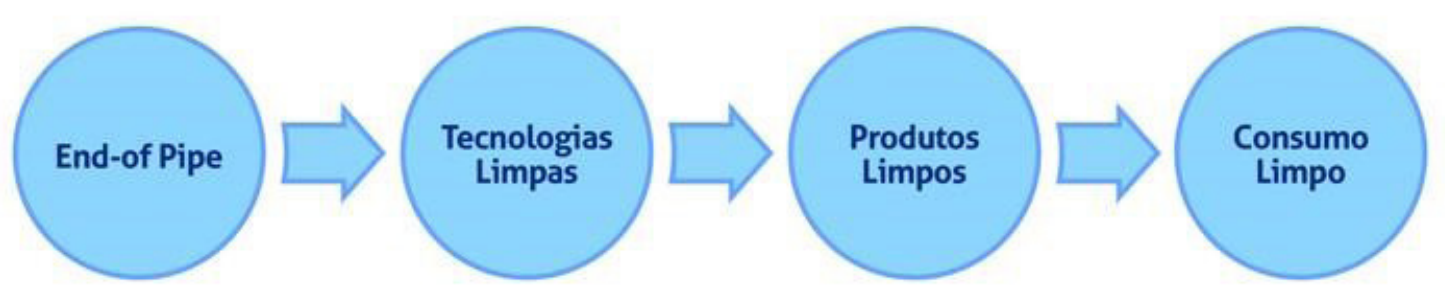

Figura 1. Evolução da abordagem ambiental no design de produto.

A sustentabilidade é um assunto muito discutido e deixou de ser novidade. Entretanto, corre o risco de ser adicionada ao modismo ou torne-se apenas um rótulo, sem que sua essência fique realmente impregnada nas ações das empresas e profissionais.

O alcance da sustentabilidade envolve as mais diversas áreas do conhecimento: das ciências sociais aplicadas às engenharias, passando pelas ciências humanas, exatas, entre outras. Requer abordagens interdisciplinares, multidisciplinares e transdisciplinares.

No aspecto profissional, estar ciente e atualizado sobre o tema tornou-se cada vez mais importante. Espera-se que cada pessoa seja capaz de reconhecer sua parcela de responsabilidade, do que pode fazer para contribuir, independente do tipo de atividade profissional exercida. A sustentabilidade atua como um elo social, no qual cada ação individual tem efeito compartilhado por todos.

Por estas razões, a incorporação da variável sustentabilidade em atividades projetuais é assunto consideravelmente debatido na atualidade, sendo consenso entre os autores da área que a sustentabilidade deve ser alicerçada (para que tenha efeito 
permanente e não apenas esporádico ou superficial), na união das três dimensões básicas: econômica, social e ambiental (LIBRELOTTO, 2009).

Hansen e outros (2010) explicam que a conscientização da sociedade por um desenvolvimento sustentável uniu-se à busca pelo aumento do desempenho ambiental das organizações. Isso estimulou a evolução de uma linha de pensamento que prima avaliar o saldo ambiental de produtos e serviços, por meio de uma abordagem ampla das inter-relações entre os sistemas e o meio ambiente. Passou a ser conhecida por Avaliação do Ciclo de Vida (ACV).

Tanto no meio acadêmico quanto no industrial, o tema "sustentabilidade" tem sido inserido gradualmente. É difícil encontrar no mercado algum evento (capacitações, treinamentos, programas de pós-graduação, cursos de aperfeiçoamento, palestras, simpósios, feiras, etc.) que não incluam a questão da sustentabilidade como foco de discussão. Outra constatação que comprova o aumento do interesse do tema é na quantidade de artigos enviados aos congressos, eventos e periódicos, onde a área da sustentabilidade teve acréscimo considerável nas publicações. Contudo, apesar desse incremento, a compreensão necessária do tema ainda esbarra em dois aspectos interligados: a complexidade dos fatores envolvidos, e o desconhecimento das variáveis e condicionantes interligados.

Conforme destacam Kubota e outros (2014), a maioria dos artigos (63\%) são de caráter teórico, que propõe métodos e modelos conceituais de desenvolvimento de produtos, considerando aspectos de projeto técnico alinhados a aspectos do ecodesign, por vezes denominado design sustentável, seguidas de estudo ou análise de casos para a avaliação dos modelos propostos. Há, portanto, carência de abordagens e aplicações práticas, preferencialmente sob a forma de extensão universitária, fortalecendo o vínculo pesquisa - ensino - extensão.

Como forma de integrar a sustentabilidade na atividade projetual, sobretudo nas etapas de modelagem, o objetivo geral da pesquisa relatada neste artigo foi demonstrar a importância do uso dos modelos volumétricos para análise da sustentabilidade, considerando as variáveis da sustentabilidade descritas no modelo ESA.

\section{Contextualização e problemática}

De modo constante, engenheiros e projetistas estão incorporando a questão ambiental na indústria. Faz parte da própria evolução conceitual da melhoria contínua, que iniciou com Taylor (emprego da metodologia científica no processo de produção, integrando as áreas de administração e engenharia), passando pelo movimento werkbund, na Alemanha, pela evolução do conceito de ergonomia de produto (década de 1950), iniciação e aplicação dos princípios da qualidade total (gestão da qualidade total, gestão da produtividade total, gestão dos custos total, gestão da tecnologia total, gestão dos recursos total) dos chamados gurus da qualidade (W. E. Deming, Kaoru Ishikawa, Philip B. Crosby, Armand Feigenbaum e Joseph W. Juran entre outros) e finalmente a globalização da economia e as associações internacionais de comércio buscando uma padronização internacional.

A conseqüência básica mais aceita desses fatores foi uma alteração do modo como o conhecimento necessário aos profissionais de projeto precisava ser trans- 
mitido e aplicado, mudando-se o paradigma informativo para o do conhecimento obtido através da pesquisa. Desse modo, os métodos e ferramentas de projeto optaram por um maior grau de liberdade nas etapas iniciais de projeto (onde a criatividade é alimentada por técnicas específicas), aumentando as "restrições" à medida que o projeto evolui para os estágios finais, favorecendo a integração multidisciplinar.

Back et al (2008), Pahl et al (2005) e Callister Jr. (2006) são exemplos típicos desta evolução, pois mostram processos de desenvolvimento de produtos que integram questões subjetivas (mais associadas as ciências sociais aplicadas como o design) com questões quantitativas (oriundas das engenharias). A questão ambiental acaba por associar-se entre ambas, como um elo que tende a fortalecer a interdisciplinaridade necessária. Logo, percebe-se um campo amplo de atuação integrando as variáveis da sustentabilidade contidas no modelo ESA (LIBRELOTTO, 2009), passando a atividade de design a ter a inclusão das variáveis ambientais, econômicas e sociais de forma integrada no projeto de produtos.

Depois de uma revisão conceitual, Santos (2000) afirma ser o design um sistema processador de informações, onde existe uma entrada e uma saída. Neste sistema, tanto os insumos quanto os resultados obtidos são informações, ou seja, o processo de design é alimentado por informações de várias áreas (engenharia, produção, ergonomia, marketing, sociologia, economia, entre outros), e após o processamento, serão obtidas mais informações, que permitirão posicionar o produto projetado no mercado frente a concorrentes e consumidores. Essa abordagem evoluiu para a metodologia projetual conhecida como MD3E (Método de Desdobramento em 3 Etapas) ou Método Aberto de Design (SANTOS, 2005), conforme ilustra a figura 2, adaptada de Santos (2005). O emprego do conceito de método aberto de design proposto pelo autor é pioneiro no Brasil e buscou sanar a problemática da necessidade interdisciplinar de atuação dos novos projetistas, que precisam navegar entre conceitos abstratos e concretos sem deixar de considerar a questão ambiental.

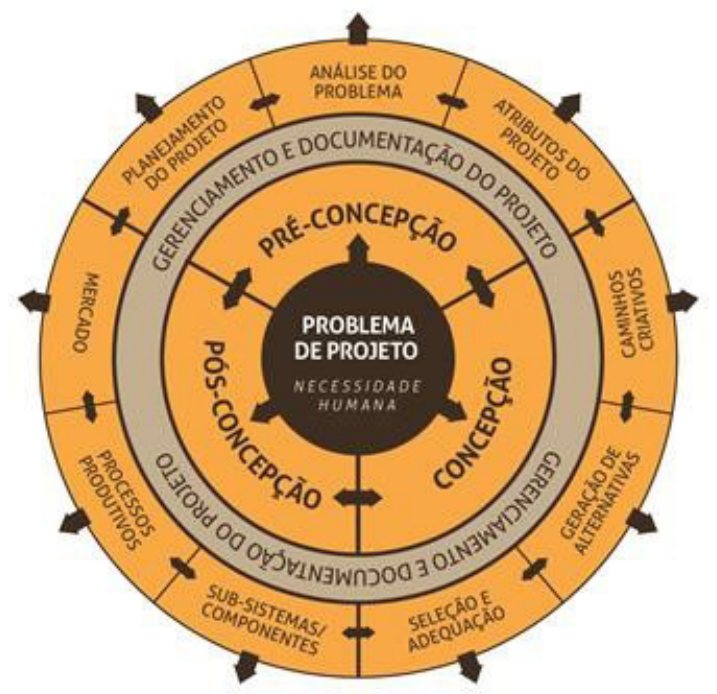

Figura 2. Metodologia MD3E.

Nas novas definições apresentadas para design, observa-se o sentido da pa- 
lavra qualidade envolvendo o processo de design, assim como a integração da sustentabilidade, se não no todo, parcialmente inserida na acepção. Ou seja, a busca de procedimentos sistemáticos ligados ao projeto tem por objetivo, claramente, a melhoria da qualidade do atendimento das necessidades das pessoas, obtido pela solução de um problema específico mediante o projeto de um produto. A solução, por sua vez, contempla a satisfação às necessidades considerando-se questões sociais, ambientais e econômicas.

Para viabilizar a integração dos aspectos envolvidos, conseguindo uma correlação positiva entre variáveis quantitativas e qualitativas, envolve-se as cinco maiores diretrizes dos estudos da qualidade total, que, separadamente não obtiveram o sucesso esperado nos anos 1980, mas, quando combinados em uma gestão de melhoria contínua, proporcionaram a evolução conceitual na qual a gestão do design se sustenta. As cinco diretrizes são: gestão da qualidade total, gestão da produtividade total, gestão dos custos total, gestão da tecnologia total e gestão dos recursos total, conforme encontrado em Harrington \& Harrington (1998). Pode-se acrescentar a esta pirâmide, sem medo de errar, a gestão da sustentabilidade total.

Dessa maneira, a integração mostra que o processo de design, em um ambiente que busque a garantia da satisfação do usuário mediante uma abordagem da sustentabilidade total deve envolver alguns critérios fundamentais, interdependentes entre si, mas com características únicas e inseparáveis, conforme se pode ver na tabela 1, adaptada de Ferroli (2009).

TABELA 1 - Critérios gerais para design multidisciplinar.

\begin{tabular}{|c|l|}
\hline CRITÉRIOS & \multicolumn{1}{c|}{ DESCRIÇÃO } \\
\hline $\begin{array}{c}\text { De fabricação e } \\
\text { produção industrial }\end{array}$ & $\begin{array}{l}\text { O projeto deve originar um produto fabricável e que respeite as restrições re- } \\
\text { ferentes aos materiais que serão utilizados na sua produção. Além disso, deve } \\
\text { atentar aos métodos de fabricação disponíveis, as máquinas necessárias para } \\
\text { do produto e a flexibilidade produtiva necessária para o atendimento de even- } \\
\text { tuais mudanças comportamentais, do consumidor ou por questões legais ou } \\
\text { restrições mercadológicas. }\end{array}$ \\
\hline De mercado e pú- \\
blico-alvo & $\begin{array}{l}\text { Aspectos referentes à regionalização e às expectativas próprias de cada po- } \\
\text { pulação influenciam tanto quanto aspectos técnicos. O marketing do produ- } \\
\text { to e a necessidade da observação contínua dos produtos concorrentes, bem } \\
\text { como novas tendências de materiais, formas, cores e estilos. }\end{array}$ \\
\hline De fluxo de caixa & $\begin{array}{l}\text { Os custos são fortemente influenciados pelos processos fabris e característi- } \\
\text { cas mercadológicas. São influenciados pela aquisição de maquinário, projetos } \\
\text { de dispositivos ou ferramental complementar de chão de fábrica e os treina- } \\
\text { mentos e capacitações da mão-de-obra. Também devem ser considerados os } \\
\text { gastos com materiais que serão usados no produto e os gastos que envolvem } \\
\text { o processo de produção (energia elétrica, água, controle de resíduos, trata- } \\
\text { mentos superficiais e térmicos, e outros). }\end{array}$ \\
\hline
\end{tabular}




\begin{tabular}{|c|l|}
\hline CRITÉRIOS & \multicolumn{1}{c|}{ DESCRIÇÃO } \\
\hline $\begin{array}{c}\text { De apresentação do } \\
\text { produto }\end{array}$ & $\begin{array}{l}\text { A primeira relação do usuário com o produto que está adquirindo é visual e a } \\
\text { primeira intenção na escolha de um produto, feita pela maioria das pessoas, é } \\
\text { a questão da estética. Posteriormente, a primeira impressão pode ser modifi- } \\
\text { cada por outros critérios, como por exemplo, os fatores ergonômicos (sensa- } \\
\text { ção de conforto proporcionado pelo produto), fatores financeiros (preço do } \\
\text { produto) e a tendência da "moda" atual (que pode influenciar desde detalhes } \\
\text { e cores, até o material empregado no produto). }\end{array}$ \\
\hline $\begin{array}{c}\text { De conforto e segu- } \\
\text { rança do produto }\end{array}$ & $\begin{array}{l}\text { A satisfação do usuário está diretamente relacionada à percepção de conforto } \\
\text { existente no produto, que por sua vez proporciona a segurança devida. De- } \\
\text { ve-se levar em conta o uso inesperado do produto, além da observação das } \\
\text { medidas antropométricas, biomecânica e cognição }\end{array}$ \\
\hline $\begin{array}{c}\text { De relação ecológi- } \\
\text { ca e ambiental }\end{array}$ & $\begin{array}{l}\text { São os relacionados ao conceito de eco-design, que consideram os índices } \\
\text { de reciclabilidade dos materiais empregados; a possível reutilização dos ma- } \\
\text { teriais; a redução de componentes e gastos energéticos. }\end{array}$ \\
\hline
\end{tabular}

Estes critérios, se agrupados de forma diferente, contemplam a tríade ESA da sustentabilidade e devem ser analisados pelo projetista considerando-se o ciclo de vida do produto.

\section{O uso de modelos físicos em design de produtos}

Usamos modelos em diversas etapas do desenvolvimento de novos produtos. Podem ser um excelente meio para apresentar o novo produto aos consumidores potenciais e outras pessoas da empresa. Podem ajudar o designer a desenvolver novas ideias, principalmente quando se trata de produtos com complexidade tridimensional, que dificilmente seriam visualizados em papel ou na tela do computador. Eles podem ser usados também para visualizar a integração entre os diversos componentes do produto.

Das diversas classificações existentes, pode-se dizer que existem alguns tipos específicos de modelos e protótipos: o comportamental (enfatiza a exploração de determinados comportamentos), o estrutural (explora questões arquiteturais ou tecnológicas), o exploratório (cujo nome é autoexplicativo) e o evolutivo (que gradualmente evolui para se tornar um produto real).

À medida que acontece o desenvolvimento do produto, aumenta-se o nível das informações e se reduz os riscos. Por isso é que o modelo evolutivo aumenta de sofisticação e complexidade.

Os modelos físicos são representações tridimensionais de objetos ou produtos em fase de desenvolvimento. Servem para simular determinadas propriedades dos objetos em estudo, permitindo corrigir defeitos e insuficiências do produto durante as etapas de projeto. Os modelos podem servir para gerar os moldes ou matrizes que irão produzir os objetos; para avaliar o desempenho dos produtos no uso a que se destinam antes de serem produzidos industrialmente ou ainda para estudar as reações do mercado ao produto, antes que este entre em processo de produção.

Sucintamente, Penna (2002) apresenta uma classificação interessante para os 
modelos físicos em design de produto:

- Modelos preliminares: também chamados de pré-modelos, são quase que exclusivos para avaliação volumétrica. São gerados a partir de um esboço ou estudo preliminar e podem ser executados em qualquer material, que não tenha relação com o produto final. Nestes, não são considerados detalhes formais, estruturais ou construtivos. Os materiais geralmente empregados neste tipo de modelos devem ser de baixo custo, recicláveis ou descartáveis, de fácil manuseio e que permitam alterações formais rápidas.

- Mock-up: ou modelo experimental. Realizado em escala natural (1:1), é usado para testes ergonômicos, funcionais ou verificação de níveis de acabamento e/ou testes. Podem ser realizados de diversos materiais, dentre eles chapas finas de PS (Poliestireno), chapas finas de PP (Polipropileno), chapas finas de PEAD (Polietileno de Alta densidade), chapas finais de madeiras transformadas (MDF principalmente), além dos já mencionados nos modelos preliminares, com maior grau de fidelidade.

- Modelo em escala reduzida ou maquete: são usados, como o próprio nome indica, para escalas reduzidas dos projetos, principalmente usados pela Arquitetura e Engenharia. São usados basicamente para promoção do produto, estudo de cores, avaliação de formas, testes de aerodinâmica, etc..

- Protótipo: significa o primeiro de um tipo. É uma das últimas etapas de um projeto, devendo ser realizado em escala natural, de modo absolutamente igual ao produto final, ou seja, utilizando inclusive os mesmos materiais e acabamentos superficiais, devendo funcionar adequadamente. Sua confecção pode ser artesanal ou industrial. O protótipo também serve para "disparar" a produção em série.

Independente do método projetual adotado, o uso da modelagem está presente em várias etapas do processo de design. Back et al (2008) mostram a estrutura de um processo projetual, onde pode-se perceber a importância e o momento adequado de utilização de modelos e protótipos (Figura 3). A mesma abordagem é mostrada em Rozenfeld et al (2006), ilustrada na Figura 4.

Observa-se, na Figura 3, que os autores colocam o uso de protótipos como uma das atividades de projeto preliminar. No entanto, isso não significa que o designer não usará modelos de menor complexidade em etapas anteriores (projeto informacional e projeto conceitual), como está representado ao integrar-se o uso de modelos e protótipos como integrantes da metodologia de projeto. Na etapa de projeto informacional, por exemplo, ao final da aplicação do QFD, pode ser muito útil o emprego de modelos volumétricos e de estudos formais (detalhes estéticos, cores, texturas, etc.). Do mesmo modo, durante a etapa descrita como projeto detalhado pode-se recorrer, sempre que necessário, ao emprego de modelos: simples, detalhados, funcionais ou mesmo protótipos. 


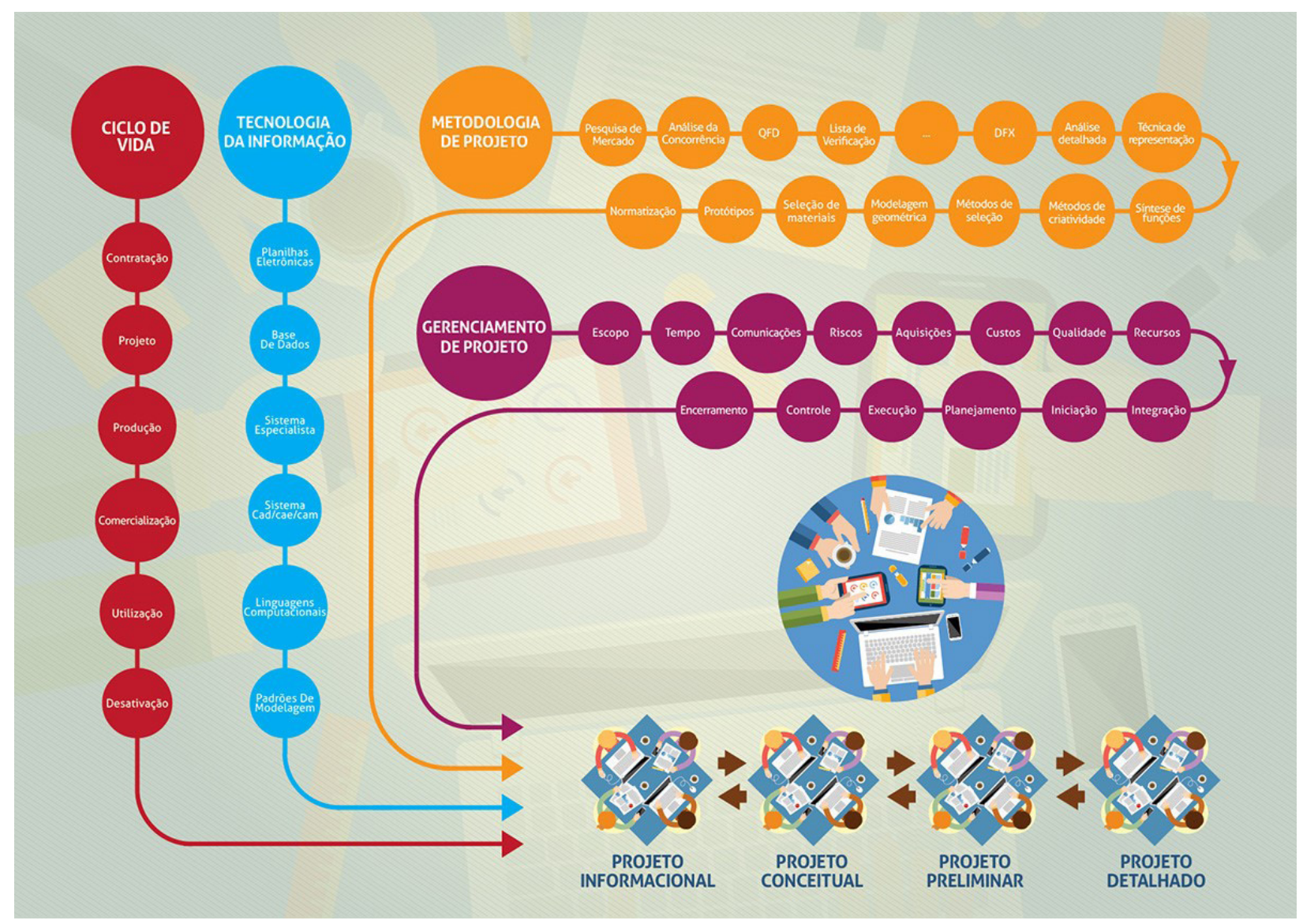

Figura 3. Estrutura de projeto

Cabe ressaltar que nem sempre é necessário o emprego de um modelo ou protótipo físico, podendo o estudo ser realizado de modo virtual.

Na Figura 4 divide-se o processo projetual em cinco etapas: projeto informacional, projeto conceitual, projeto detalhado, preparação para produção e lançamento do produto, ao invés das quatro propostas anteriormente. De acordo com Rozenfeld et al (2006), a utilização de modelos e protótipos deve ser adequada à complexidade e fatores relevantes a cada projeto específico.

\section{Sustentabilidade aplicada em modelos volumétricos}

A garantia da sustentabilidade envolve o equilíbrio entre três dimensões: econômica, social e ambiental. Assim, deve-se buscar o lucro que permita a satisfação dos interesses de todos os intervenientes do processo: os investidores devem ter o retorno financeiro, a comunidade local deve usufruir dos benefícios da atividade empresarial, os funcionários devem ter seu retorno em qualidade de vida e equidade social, 


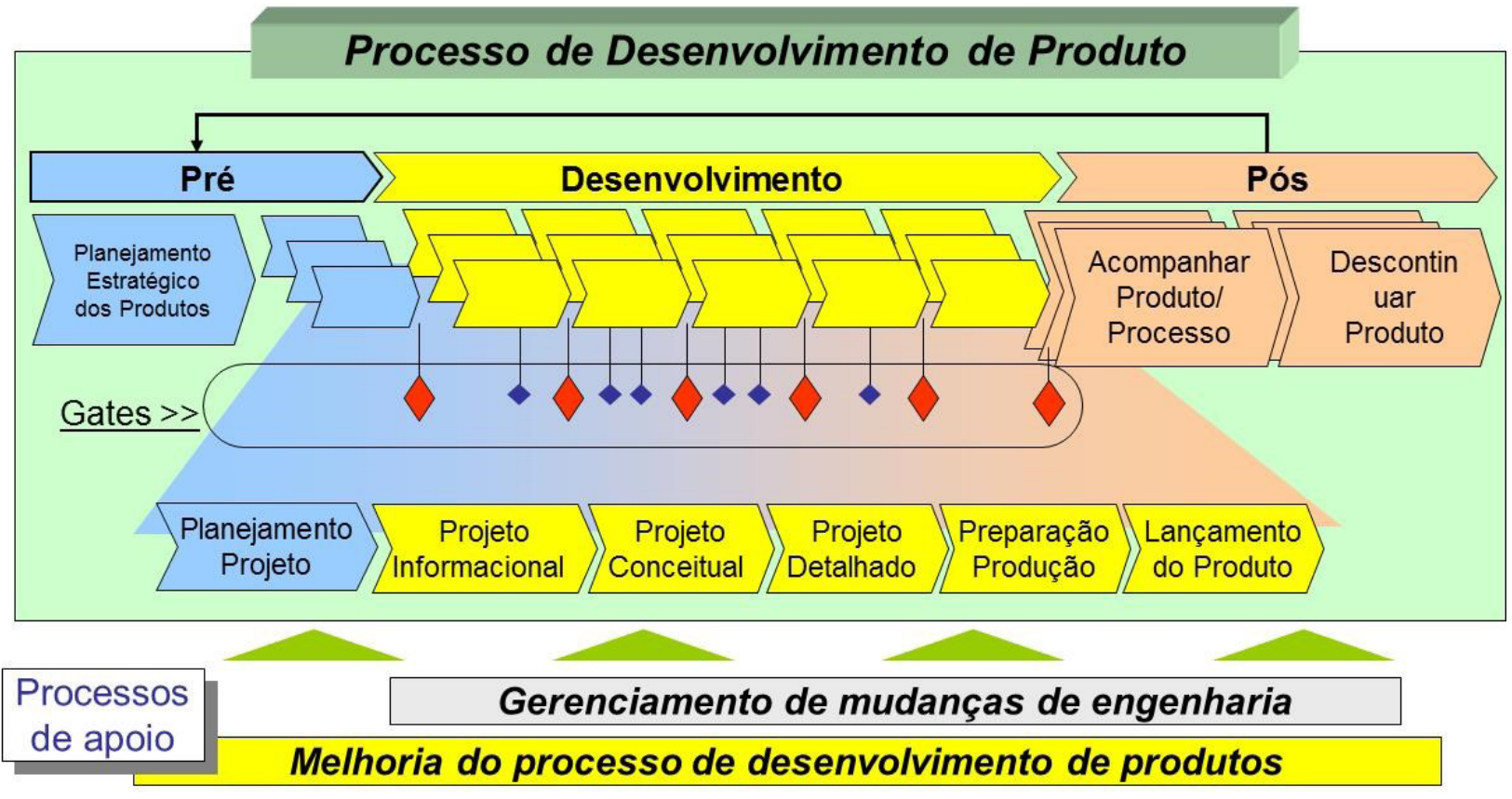

Figura 4. Processo de Desenvolvimento de Produto.

e tudo isso, não deve prejudicar (ou pelo menos os impactos devem ser minimizados) o meio ambiente, do qual todos necessitam para sobreviver.

Tal realidade sustentável parece um pouco distante, assim como eram os conceitos da qualidade total e a preservação ambiental, até bem pouco tempo atrás. No entanto, a ISO 9000 é, atualmente, uma realidade em quase todos os setores industriais. A ISO14000 também tem impulsionado empresas rumo à certificação ambiental, assim como a BS8800 e a SA8000 têm auxiliado na busca por melhores condições de saúde, segurança no trabalho e pela responsabilidade social.

Segundo Librelotto (2009), sustentabilidade é o princípio que assegura que nossas ações hoje não limitem o alcance das opções econômica, social e ambiental para as futuras gerações. Baseado neste conceito e no modelo SPC (Scherer e Ross,) o modelo ESA (LIBRELOTTO, 2009), utiliza a sustentabilidade em três dimensões:

- Dimensão social: envolve os preceitos da responsabilidade social e gestão de pessoas na estrutura - conduta - desempenho da indústria.

- Dimensão ambiental: associa a estrutura-conduta-desempenho da indústria à preservação do ecossistema ou minimização dos impactos das atividades industriais sobre este.

- Dimensão econômica: associa a estrutura-conduta-desempenho à garantia de retorno dos investimentos aos intervenientes do processo (proprietários, clientes, funcionários e comunidade em geral).

Considera-se que, para alcançar um desempenho sustentável, deve haver o equilíbrio entre o desempenho alcançado nas dimensões econômica, social e ambiental e o desenvolvimento de ações (condutas) para estas três dimensões, conforme a proposta de Elkington (1998) apud Librelotto (2009). O desempenho de uma empresa, por exemplo, sofrerá influência das condutas adotadas, que por sua vez, são reflexo da estrutura da indústria na qual a empresa está inserida, das capacidades internas da organização e dos choques externos ocorridos sobre a estrutura industrial. 
Originalmente desenvolvido para avaliar a sustentabilidade em empresas atuantes no setor da construção civil, o Modelo ESA tem sido adaptado para outros setores e utilizado em diferentes aplicações. Uma dessas adaptações refere-se à sua aplicação na avaliação da sustentabilidade de produtos.

A forma como deve ser realizado o correlacionamento das dimensões ESA (Econômica, Social e Ambiental) está expressa na Figura 5, através do cubo de avaliação da sustentabilidade, adaptado de Librelotto (2009). O posicionamento da empresa e ou produto será avaliado conforme a localização nos cubos, que identificam os estados transitórios definidos originalmente no modelo como derrotada, sofrível, responsável, indiferente, oportunista ou pioneira, conforme sua posição no cubo de correlação.

Existe uma tendência teórica de deslocamento do objeto da avaliação para os quadrantes nos extremos do cubo. No entanto, é difícil que o objeto se desloque da parte inferior do cubo para o superior ou vice-versa, sem que ocorra uma mudança nas condições de mercado.

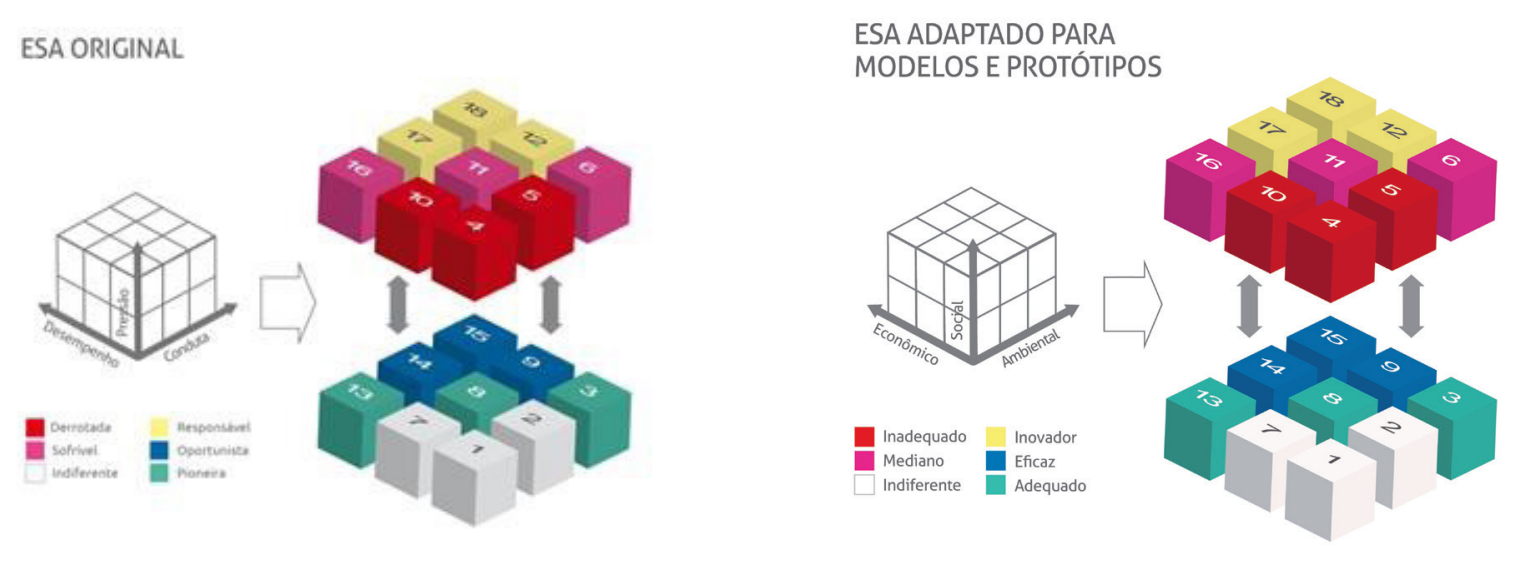

Figura 5. Avaliação do posicionamento das empresas.

\section{Método de pesquisa}

Este item apresentará a aplicação do modelo ESA de sustentabilidade em modelos e protótipos desenvolvidos em projetos de design de produto. Quanto à adaptação do modelo ESA para o caso específico de modelos e protótipos, o eixo de desempenho avaliou o critério econômico da sustentabilidade; o eixo da conduta avaliou o critério ambiental da sustentabilidade e o eixo referente às pressões avaliou o critério social da sustentabilidade. A posição no cubo determinará o grau de "sustentabilidade" do modelo segundo uma abordagem ampla, contemplando as três variáveis: econômica, social e ambiental. Na verdade, assume-se que cada eixo (estrutura, conduta e desempenho) possui também um cubo de correlação no que se refere ao econômico, social e ambiental.

Para a realização dos experimentos práticos, utilizou-se dos trabalhos desenvolvidos em disciplinas de graduação em Design Industrial, Design de Produto e Arquitetura e Urbanismo. Foram escolhidos aleatoriamente alguns modelos para teste e validação da adaptação original do modelo ESA, dos quais seis foram mostrados neste artigo. 
Para o caso específico de análise de modelos / protótipos de design foi necessário uma adaptação das nomenclaturas utilizadas na modelo ESA original, aplicado na indústria da construção civil. Iniciando onde as pressões do mercado (que, neste caso, representa a questão social da sustentabilidade), são pequenas, tem-se:

- o termo "pioneira" foi substituído por "adequado", ou seja, representa um modelo e/ou protótipo construído dentro de princípios modernos de sustentabilidade, considerando-se os critérios econômico e ambiental, já que a questão social não é forte.

- o termo "oportunista" foi substituído por "eficaz", que representa um modelo e/ou protótipo construído dentro do esperado do ponto de vista econômico e ambiental, em um ambiente social que não apresenta pressões demasiadas.

- o termo "indiferente" será mantido e representa um modelo e/ou protótipo construído em um ambiente com pouca ou nenhuma pressão do ponto de vista social, sendo nele usados materiais normais, sem a ocorrência de preocupação demasiada com os aspectos ambiental ou econômico dos materiais utilizados. No entanto, tanto do ponto de vista econômico quanto ambiental, não foram usados materiais muito caros ou comprovadamente nocivos, por exemplo, ou seja, o modelo não inova, mas também não compromete.

Onde as pressões de mercado são maiores, e por isso, as conseqüências equivocadas da escolha dos materiais dos modelos e/ou protótipos serão mais graves, tem-se as seguintes alterações:

- o termo "derrotada" foi substituído por "inadequado", representando um modelo e/ou protótipo projetado e executado de forma incorreta, com custo muito elevado e utilização de materiais nocivos ao meio ambiente.

- o termo "sofrível" foi substituído por "mediano", e representa um modelo e/ ou protótipo que atende parcialmente à questão ambiental e econômica, em um ambiente onde as pressões sociais são elevadas, ou seja, é um modelo construído com materiais de preço elevado e de difícil reciclagem e/ou reaproveitamento, por exemplo.

- o termo "responsável" foi substituído por "inovador", representando um conceito oposto ao inadequado. É um modelo construído com materiais pré-selecionados, representando uma boa inovação, atendendo aos requisitos de projeto de forma responsável.

Para a classificação dos modelos, os itens considerados para posicionamento do modelo no cubo do ESA foram definidos conforme listagem abaixo. Foram padronizados dois critérios para cada fator: material de confecção do modelo e processo de fabricação.

A classificação do modelo e/ou protótipo segundo o modelo ESA considera como eixo x, o ambiental; eixo y, o social; e eixo z, o econômico. O primeiro passo da classificação é o posicionamento segundo a pressão social, sendo:

Eixo y: notas de 0,0 a 4,9, com possibilidades de modelos adequado, indiferente e eficaz.

Eixo y: notas de 5,0 a 10,0, com possibilidades de modelos inadequado, mediano e inovador.

Segundo passo da classificação: estabelecendo-se o posicionamento no eixo y 
(questão social fraca ou forte), as demais médias funcionarão como pares ordenados, sendo assim classificadas:

1) indiferente: pressão social fraca, fator econômico de 0,00 a 6,65 associados com um fator ambiental de 0,00 a 6,65, observando-se que, se um dos fatores estiver no cubo 7 (Figura 7) o outro fator deverá ter média máxima de 3,32 e vice-versa;

2) eficaz: pressão social fraca, um dos fatores (econômico ou ambiental) deverá estar com índice entre 6,67 a 10,00 ou ambos no mínimo entre 3,33 e 6,66;

3) adequado: pressão social fraca com ambos os fatores devendo estar com nota mínima de 6,67;

4) inadequado: mesma situação numérica que o modelo classificado como indiferente, porém aqui a pressão social é elevada;

5) mediano: mesma situação numérica que o modelo classificado como eficaz, porém aqui a pressão social é elevada;

6) inovador: mesma situação numérica que o modelo classificado como adequado, porém aqui a pressão social é elevada.

Os valores colocados nas planilhas classificatórias foram relacionados com os seguintes fatores:

- Econômicos:

1. Material de confecção do modelo: preço de aquisição do material (R\$), quantidade de material utilizado $(\mathrm{kg})$, porcentagem de aproveitamento do material considerando dimensões comerciais disponíveis no mercado (\%);

2. Processo de fabricação: quantidade de ferramentas necessárias (unidades); custo de energia elétrica (kwh x custo do kwh, em R\$), tempo de fabricação do modelo (minutos);

- Sociais:

1. Material de confecção do modelo: quantidade de fornecedores na região (unidade); disponibilidade do material - tempo de espera para efetivar a compra (dias); existência na região de materiais alternativos (de mesmo custo) na impossibilidade de uso do material de primeira escolha (sim ou não).

2. Processo de fabricação: geração de renda para a região, ou seja, se a matéria-prima empregada no modelo é fabricada na região (sim ou não); quantidade de empresas capazes de fabricar a matéria-prima empregada no modelo na região (quantidade); capacitação da mão-de-obra na região especializada na produção da matéria-prima empregada na fabricação do modelo (medida de observação qualitativa).

- Ambientais:

1. Material de confecção do modelo: possibilidade de reciclagem do material usado no modelo (\% de material do modelo que pode ser reciclado); possibilidade de reaproveitamento do material usado no modelo (\% de material do modelo que pode ser reaproveitado); origem da matéria-prima (virgem, reciclada ou mista).

2. Processo de fabricação: gasto energético total na fabricação do modelo (R\$); quantidade de subprodutos sem utilidade gerados no processo fabril (kg); quantidade de subprodutos que podem ser vendidos para reciclagem ou reaproveitamento gerados no processo fabril $(\mathrm{kg})$.

$\mathrm{Na}$ aplicação do ESA, as notas foram atribuídas mediante comparações quan- 
titativas e qualitativas com outros possíveis materiais que poderiam ter sido utilizados para a construção do modelo, respeitando-se aos requisitos técnicos e estéticos. Observa-se que, para efeito do proposto nesta pesquisa, o modelo desenvolvido em determinado material foi comparado com outros dois possíveis materiais. Limitou-se em dois somente para efeitos desta pesquisa, ressaltando-se, no entanto, que não existem limites determinados para uma aplicação prática. Para o preenchimento das planilhas utilizou-se a classificação mostrada na tabela 2.

Tabela 2. Classificação dos critérios segundo o ESA para análise dos modelos físicos.

\begin{tabular}{|c|c|c|c|c|c|}
\hline \multicolumn{2}{|l|}{ Critérios econômicos } & \multicolumn{2}{|l|}{ Critérios sociais } & \multicolumn{2}{|l|}{ Critérios ambientais } \\
\hline Critério & ESA & Critério & ESA & Critério & ESA \\
\hline $\begin{array}{l}\text { Preço de aquisição do } \\
\text { material }\end{array}$ & E1 & $\begin{array}{l}\text { Quantidade de fornecedo- } \\
\text { res na região }\end{array}$ & S1 & $\begin{array}{l}\text { Possibilidade de recicla- } \\
\text { gem do material usado no } \\
\text { modelo }\end{array}$ & A1 \\
\hline $\begin{array}{l}\text { Quantidade de material } \\
\text { utilizado }\end{array}$ & E2 & $\begin{array}{l}\text { Disponibilidade do ma- } \\
\text { terial - tempo de espera } \\
\text { para efetivar compra }\end{array}$ & $\mathrm{S} 2$ & $\begin{array}{l}\text { Possibilidade de reaprovei- } \\
\text { tamento do material usado } \\
\text { no modelo }\end{array}$ & $\mathrm{A} 2$ \\
\hline $\begin{array}{l}\text { \% de aproveitamento } \\
\text { do material conside- } \\
\text { rando dimensões co- } \\
\text { merciais disponíveis no } \\
\text { mercado. }\end{array}$ & E3 & $\begin{array}{l}\text { Existência, na região, de } \\
\text { materiais alternativos } \\
\text { (mesmo custo) na impossi- } \\
\text { bilidade de uso do material } \\
\text { de primeira escolha. }\end{array}$ & S3 & Origem da matéria-prima & A3 \\
\hline $\begin{array}{l}\text { Quantidade de ferra- } \\
\text { mentas necessárias }\end{array}$ & E4 & $\begin{array}{l}\text { Geração de renda para a } \\
\text { região }\end{array}$ & S4 & $\begin{array}{l}\text { Gasto energético total na } \\
\text { fabricação do modelo }\end{array}$ & A4 \\
\hline $\begin{array}{l}\text { Custo de energia elé- } \\
\text { trica }\end{array}$ & E5 & $\begin{array}{l}\text { Quantidade de empresas } \\
\text { capazes de fabricar a ma- } \\
\text { téria-prima empregada no } \\
\text { modelo (na região) }\end{array}$ & S5 & $\begin{array}{l}\text { Quantidade de subprodu- } \\
\text { tos sem utilidade no pro- } \\
\text { cesso fabril }\end{array}$ & A5 \\
\hline $\begin{array}{l}\text { Tempo de fabricação } \\
\text { do modelo }\end{array}$ & E6 & $\begin{array}{l}\text { Capacitação da mão-de } \\
\text {-obra na região especiali- } \\
\text { zada na produção da ma- } \\
\text { téria-prima empregada na } \\
\text { fabricação do modelo }\end{array}$ & S6 & $\begin{array}{l}\text { Quantidade de subprodu- } \\
\text { tos que podem ser vendi- } \\
\text { dos para reciclagem ou re- } \\
\text { aproveitamento }\end{array}$ & A6 \\
\hline
\end{tabular}

Observações a respeito do preenchimento dos quadros de aplicação:

- preço de aquisição do material: incluiu-se nesse quesito não somente o valor do material base, mas também materiais de apoio como tintas, lixas, massa acrílica, tecido, cola, etc.

- quantidade de material utilizado e porcentagem de aproveitamento considerando dimensões comerciais disponíveis no mercado: nestes quesitos considerou-se apenas o material base.

- no fator social, a região foi delimitada como a Grande Florianópolis, incluindo os municípios de Florianópolis, São José, Biguaçu e Palhoça. 


\section{Aplicações práticas do modelo esa em modelos volumétricos}

Este item apresenta alguns modelos desenvolvidos em aulas práticas de oficina em cursos de Design Industrial, Design de Produto e Arquitetura e Urbanismo.

O primeiro modelo utilizado para teste de aplicação do modelo ESA foi desenvolvido em papelão tipo couro (pedra) pela técnica do empilhamento. A Figura 6 mostra duas etapas da construção do modelo físico desenvolvido e a tabela 3 demonstra a aplicação (teste) do modelo ESA. Para o referido modelo, os materiais de comparação para aplicação do ESA foram bloco de Poliuretano (PU) e argila.
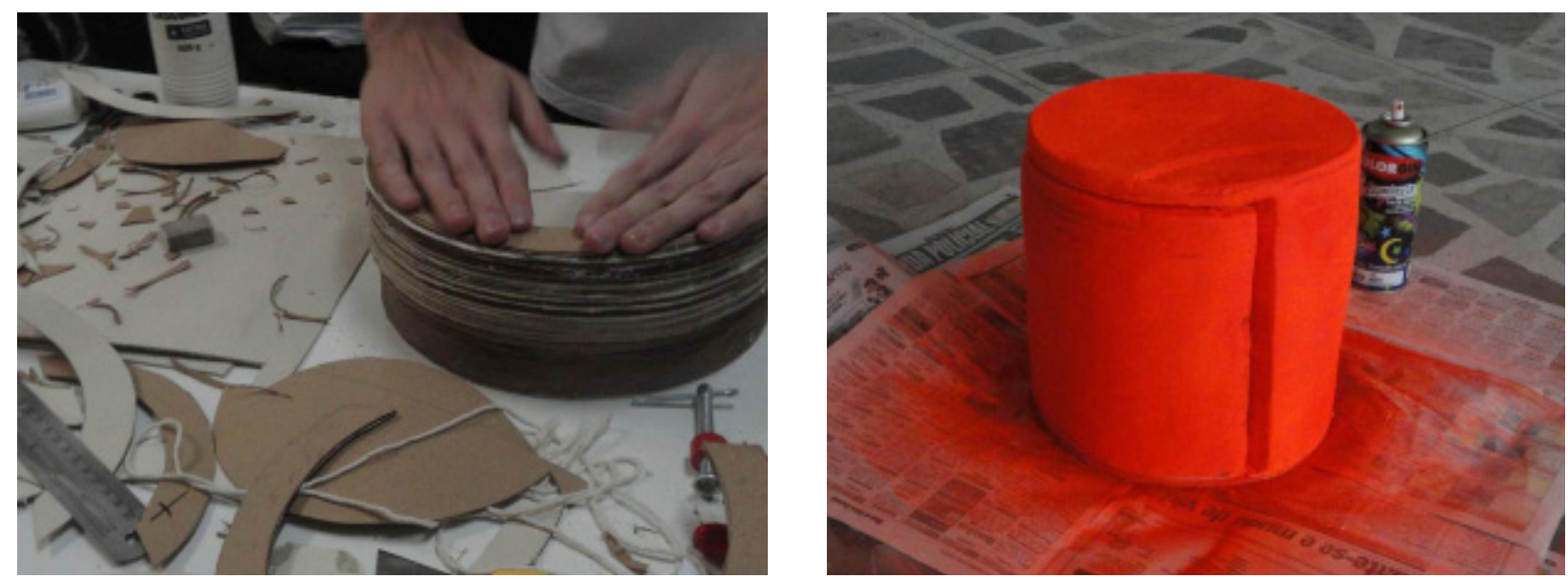

Figura 6 - Etapas de construção do modelo.

Tabela 3 - Esa aplicado ao modelo

\begin{tabular}{|c|c|c|c|c|c|c|c|c|c|c|c|c|c|c|}
\hline \multicolumn{15}{|c|}{ АРLССАС̆̈О DO U } \\
\hline & \multicolumn{3}{|c|}{ 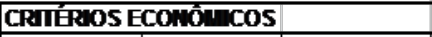 } & \multirow[b]{2}{*}{ Mota } & & \multicolumn{3}{|c|}{ CRalíraOS SOCWNS } & \multirow[b]{2}{*}{ Mota } & & \multicolumn{3}{|c|}{ CRAÍRAOS AMBEIINS } & \multirow[b]{2}{*}{ Mota } \\
\hline & \begin{tabular}{|l|l|} 
Papelāo \\
\end{tabular} & $A_{1} \mathbf{z a}$ & PU & & & Papelian & $\mathrm{Alg}_{\mathrm{g}} \mathbf{a}$ & PU & & & Papelāo & Agla & PU & \\
\hline E1 & R\$ 21,00 & Rs 12,00 & RS 65, (10) & 5,00 & S1 & 4 & 5 & 5 & 7,00 & A1 & 507 & $0 \times$ & $\mathbf{0 x}$ & 7,000 \\
\hline E2 & $98 \mathrm{~g}$ & $245 \mathrm{~g}$ & 134g & 8,00 & $\mathbf{5 2}$ & 1 & 1 & 2 & 6,000 & A2 & $8 \mathbf{8 x}$ & $\mathbf{0 x}$ & $60 x$ & 7,00 \\
\hline $\mathbf{E 3}$ & 907 & $\mathbf{9 0 x}$ & $85 \%$ & 7,000 & 53 & mitos & ximios & poucos & 9,00 & $\mathbf{A 3}$ & IEcichata & ingem & vingem & 8,00 \\
\hline E4 & $\mathbf{9}$ & 6 & 7 & 7,00 & 54 & nลิจ & pouco & nลิอ & 5,00 & $\mathbf{M}$ & RS 4,90 & RS 5,90 & RS 7,45 & 7,000 \\
\hline E5 & RS 3,32 & Rs 1,76 & RS 4,00 & 6,00 & 55 & sin & ] & 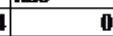 & 4,00 & A5 & $0 \%$ & $10 x$ & $55 \%$ & 5,00 \\
\hline E6 & $156 \mathrm{~min}$ & $146 \mathrm{~min}$ & $187 \mathrm{~min}$ & 7,00 & 56 & กล̄o há & médio & nẫ há & 5,00 & A6 & $20 \%$ & $\mathbf{0 x}$ & $\mathbf{0 x}$ & 7,00 \\
\hline Média & & & & 6,67 & & & & & 6,00 & & & & & 6,83 \\
\hline
\end{tabular}

Pela análise da planilha, a pressão social é alta. Considerando-se então as demais notas obtidas, o modelo foi classificado como mediano.

Dentre vários modelos desenvolvidos, selecionaram-se alguns para demonstrar neste artigo. O segundo modelo escolhido foi desenvolvido originalmente em resina de poliéster, após foram realizados modelos em PU e em clay para comparação do método. A Figura 7 ilustra os modelos: preto (resina de poliéster), creme (PU) e cinza (clay). A aplicação do ESA no modelo está registrada na tabela 4. A consideração de análise foi considerando o modelo em resina de poliéster como escolhido para fabricação e os demais para efeitos comparativos. 

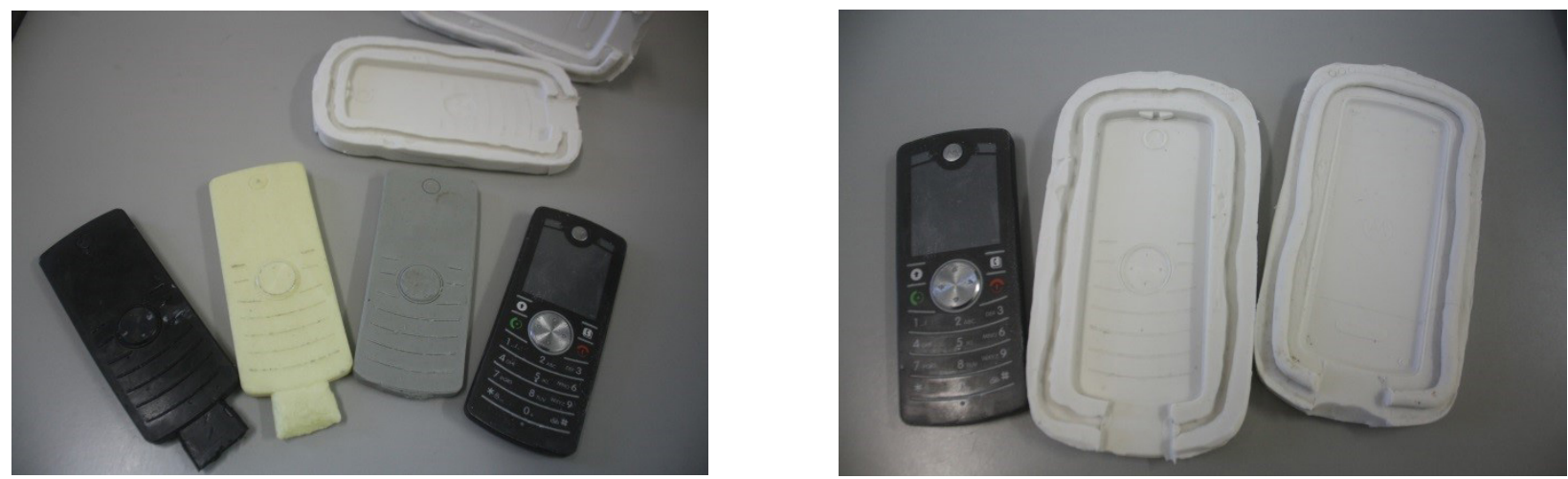

Figura 7. Modelos desenvolvidos em resina, clay e PU.

Tabela 4. ESA aplicado ao modelo.

APLICACÄO DO MODELO ESA - MODELO 2

\begin{tabular}{|c|c|c|c|c|c|c|c|c|c|c|c|c|c|c|}
\hline \multirow{2}{*}{ AT } & \multicolumn{4}{|c|}{ CRITÉRIOS ECONÓMICOS } & \multicolumn{5}{|c|}{ CRITÉRIOS SOCIAIS } & \multicolumn{5}{|c|}{ CRITÉRIOS AMBIENTAIS } \\
\hline & Resina & Clay & $\mathrm{PU}$ & Nota & & \begin{tabular}{|l|} 
Resina \\
\end{tabular} & Clay & $\mathrm{PU}$ & \begin{tabular}{|l|l|} 
Nota \\
\end{tabular} & & Resina & Clay & $\mathrm{PU}$ & Nota \\
\hline E1 & RS 37,00 & $\mathrm{R} \$ 22,00$ & R\$ 33,00 & 5,00 & S1 & 2 & 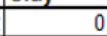 & 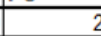 & 7,00 & $\overline{\mathrm{A} 1}$ & $0 \%$ & $0 \%$ & $20 \%$ & 7,00 \\
\hline E2 & $76 \mathrm{~g}$ & $121 \mathrm{~g}$ & $89 \mathrm{~g}$ & 8,00 & S2 & 1 & & 2 & 8,00 & $\mathrm{~A} 2$ & $0 \%$ & $30 \%$ & $60 \%$ & 3,00 \\
\hline E3 & $90 \%$ & $90 \%$ & $85 \%$ & 7,00 & S3 & poucos & nenhum & poucos & 9,00 & A3 & virgem & virgem & virgem & 5,00 \\
\hline E4 & 4 & & 7 & 6,00 & S4 & não & não & não & 5,00 & A4 & $\mathrm{R} \$ 1,10$ & RS 1,45 & R\$ 5,43 & 8,00 \\
\hline E5 & $\begin{array}{r}\mathrm{RS} 1,89 \\
\end{array}$ & RS 1,22 & $\mathrm{R} \$ 1,10$ & 6,00 & S5 & 0 & 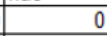 & 0 & 5,00 & A5 & $0 \%$ & $10 \%$ & $30 \%$ & 6,00 \\
\hline E6 & $108 \mathrm{~min}$ & $180 \mathrm{~min}$ & $134 \mathrm{~min}$ & 8,00 & S6 & não há & não há & pouco & 5,00 & A6 & $0 \%$ & $0 \%$ & $0 \%$ & 5,00 \\
\hline Média & & & & 6,67 & & & & & 6,50 & & & & & 5,67 \\
\hline
\end{tabular}

Pela análise da planilha, a pressão social é alta. Considerando-se então as demais notas obtidas, o modelo foi classificado como mediano também.

Foram realizados testes de aplicação do modelo ESA em 22 modelos físicos até o momento. Mediante análises pelos estudos de caso apresentados aqui, percebe-se que o modelo ESA adaptado para análise de modelagem física em design e arquitetura pode trazer boas informações para que o designer possa analisar, do ponto de vista da sustentabilidade, o modelo gerado. Consequentemente, essa análise pode ser ampliada para o escopo de todo projeto, abrangendo todo o ciclo de vida do produto. O quadro 1 ilustra alguns dos modelos físicos construídos para testes de aplicação do ESA.

QUADRO 1 - alguns modelos onde foi testado o ESA adaptado.

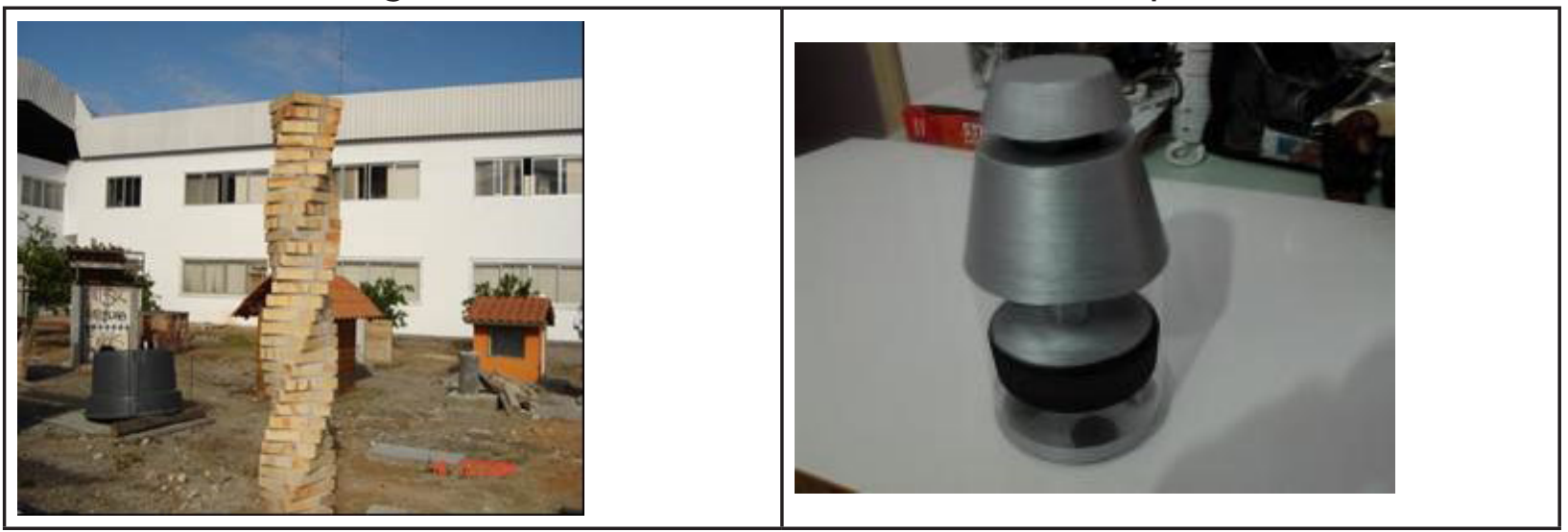




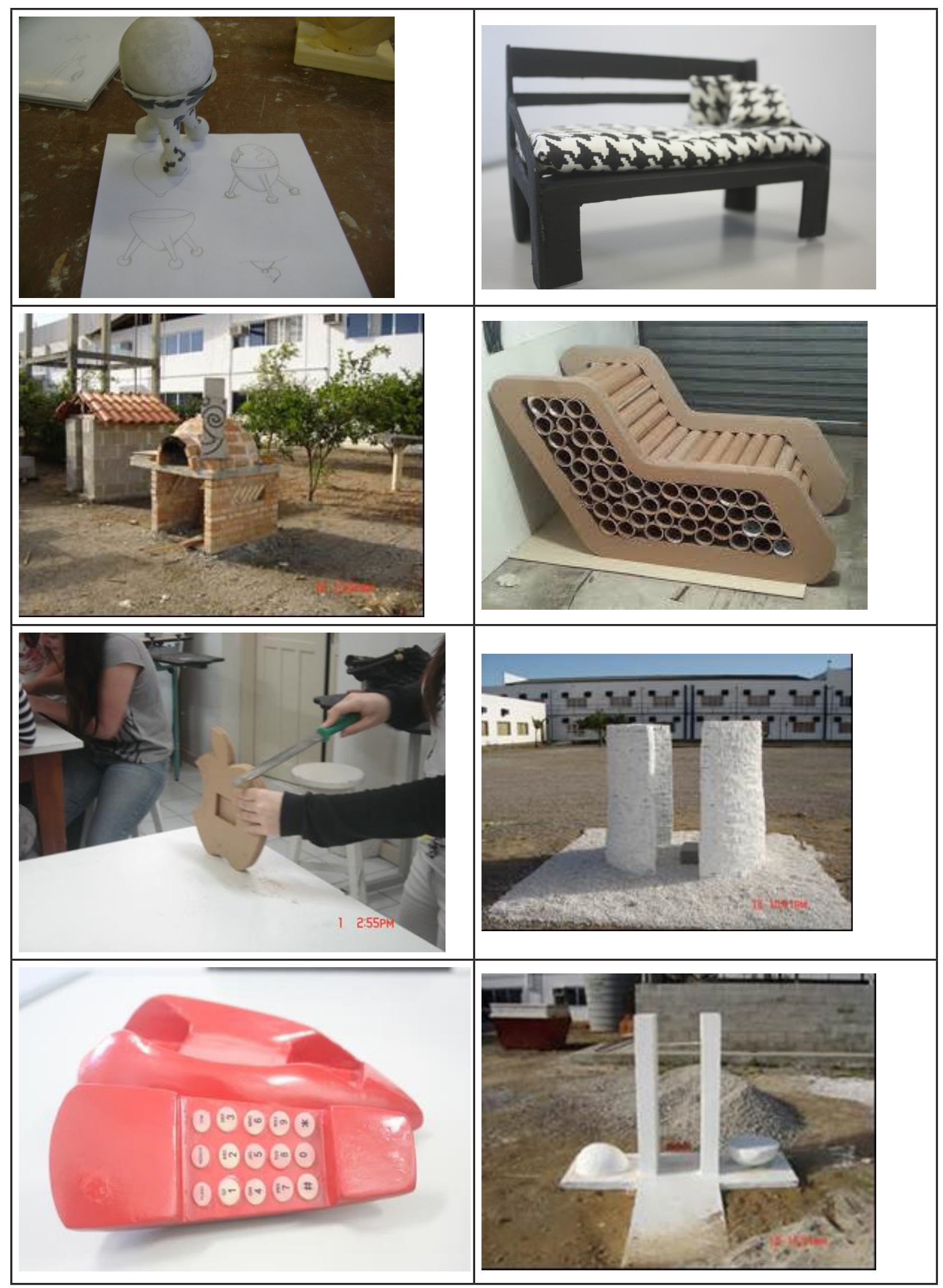




\section{Considerações finais}

Através das análises decorrentes da presente pesquisa, viu-se que a escolha dos materiais utilizados na confecção de modelos físicos e/ou protótipos utilizados em design de produtos é mais do que a consideração de atributos técnicos e produtivos. Um bom produto precisa atender a necessidades de todos os grupos de usuários, envolvendo aspectos produtivos, econômicos, ergonômicos, sociais, ambientais e estéticos, e os materiais adequados a esse modelo devem estar em conformidade com estes aspectos.

O modelo ESA, originalmente concebido para aplicação na construção civil, pode ser adaptado a contento no intuito de fornecer aos designers um modo quantitativo / qualitativo de avaliar a sustentabilidade nas dimensões econômica, social e ambiental.

Pela aplicação vista, pode-se enumerar as seguintes considerações:

- a adaptação do modelo ESA desenvolvido por Librelotto (2009) mostrou-se satisfatório para análise dos modelos físicos e/ou protótipos em design, permitindo uma abordagem global da sustentabilidade;

- o preenchimento correto das planilhas originadas é muito importante. Devido à natureza das variáveis, pequenas oscilações podem alterar o posicionamento do modelo/protótipo no cubo de classificação, podendo ocasionar conclusões precipitadas e incorretas;

- é necessário um novo estudo propondo ponderação das variáveis sob a forma de pesos, testando-se a ferramenta GUT (Gravidade - Urgência - Tendência) para que se possam analisar caso a caso as particularidades de cada modelo/protótipo.

Como recomendações para futuros trabalhos, deve ser observado que o modelo ESA foi constituído objetivando uma aplicação na construção civil. Os autores desse artigo perceberam no ESA uma potencialidade para analisar a sustentabilidade de qualquer produto. Há de se considerar, no entanto, as características próprias de cada setor. Devido a isso, o modelo ESA adaptado para uso em produtos de design, deve ser testado com mais profundidade. Também é necessária, antes de aplicações profissionais, a elaboração de um conjunto de diretrizes que possam orientar o designer (ou equipe de projeto) a melhor posicionamento das variáveis econômicas, sociais e ambientais no modelo gráfico do ESA.

\section{Referências}

BACK, N.; OGLIARI, A.; DIAS, A.; SILVA, J. C. da. Projeto Integrado de Produtos - Planejamento, Concepção e Modelagem. Barueri: São Paulo, 2008.

CALISTER Jr. Fundamentos da Ciência e Engenharia de Materiais - Uma abordagem integrada. 2 ed. Rio de Janeiro: LTC, 2006.

FERROLI, P. C. M. MAEM-6F (Método Auxiliar para Escolha de Materiais em Seis Fatores): Suporte ao design de produtos industriais. São Paulo: Blucher Acadêmico, 2009. 
HAUENSTEIN, Deisi Maria; KINDLIEIN JÚNIOR, Wilson. Estruturação de uma Biblioteca de Materiais : "Materioteca" . Disponível em: http://www.lume.ufrgs.br

HARRINGTON, J.; HARRINGTON, H. Gerenciamento Total de Melhoria Contínua. São Paulo: MkBooks, 1998.

KUBOTA, F. I.; CAMPOS, L. M. de S.; MIGUEL, P. A. C. Uma análise preliminar das contribuições da modularidade em produto ao eco-design. In: Revista Produção Online, Florianópolis, SC, v.14, n. 2, p. 560-592, abr./jun. 2014.

LIBRELOTTO, L. I. Modelo para Avaliação de Sustentabilidade na Construção Civil nas Dimensões Econômica, Social e Ambiental (ESA): Aplicação no setor de eficiações. São Paulo: Blucher Acadêmico, 2009.

MANZINI, E. e VEZZOLI, C. O Desenvolvimento de Produtos Sustentáveis - Os requisitos ambientais dos produtos industriais. São Paulo: EdUSP, 2008.

PAHL, G.; BEITZ, W.; FELDHUSEN, J.; GROTE, K. Projeto na Engenharia - Fundamentos do desenvolvimento eficaz de produtos, métodos e aplicações. São Paulo: Edgard Blücher, 2005.

PENNA, E. Modelagem - modelos em Design. São Paulo: Catálise, 2002.

ROZENFELD, H.; FORCELLINI, F. A.; AMARAL, D. C.; TOLEDO, J. C. de; SILVA, S. L. da; ALLIPRANDINI, D. H.; SCALICE, R. K. Gestão de Desenvolvimento de Produtos - Uma Referência para a melhoria do processo. São Paulo: Saraiva, 2006.

SANTOS, F. A. N. V. dos. O Design como Diferencial Competitivo. Itajaí: Ed. UNIVALI, 2000.

SANTOS, F. A. N. V. dos. MD3E (Método de Desdobramento em Três Etapas): Uma Proposta de Método Aberto de Projeto para Uso no Ensino de Design Industrial. Florianópolis: SC, PPGEP-UFSC 2005. 